\section{Aspirational thinking}

Henry Gee

W e've all seen the commercials. A line of figures walking from left to right, first a shambling ape on all fours; the second, semi-erect with a vague glimmer of intelligence, and perhaps holding a handaxe; further along, a tall, proud man, carrying a spear and wearing furs; and finally, a user of the latest car or washing machine. The caption will speak of advancement and progression, something like 'Evolution the Next Step'.

These advertisements reflect the popular view of evolution as a progressive force that drives an inexorable improvement. But in reality, evolution is based largely on natural selection, a handy term for the interaction between the environment, mutation and superabundance. Natural selection has neither memory nor foresight; it works only in the here and now. It is not a force, an entity separate from the materials on which it acts. Still less can it be personified.

Although one might like to blame the advertising industry for this misrepresentation, a successful copywriter will only hold a mirror up to the zeitgeist, and popular wisdom sees evolution as progressive and directed. So why, almost a century and a half after Darwin, do we still so readily accept this view of evolution as progressive?

I blame nature philosophy, a remarkable movement that flowered in Germany in the eighteenth century, and whose adherents were both acutely scientific and breathlessly romantic at the same time. In nature philosophy, all organic forms are manifestations of a cosmic compulsion towards perfection, with the human form as its ultimate destiny. As Lorenz Oken (1779-1851) put it: "What is the animal kingdom other than an anatomized man, the macrocosm of the microcosm?" No copywriter could have put it better: those evolving-human commercials are just nature philosophy brought up to date.

The most famous nature philosopher was Johann Wolfgang von Goethe (1749-1832). Although best known as a poet and dramatist, his scientific achievements were considerable and he had a profound influence on nineteenth-century biologists. Thomas Huxley's article "Nature: Aphorisms by Goethe" appeared in Nature's first issue in 1869. And yet in Goethe we see the apotheosis of nature philosophy as a romantic reaction to what we would see as scientific detachment, seeking to place man, once again, at the centre of all things, and to promote the subjective and the aesthetic in scientific observation.

Goethe's wide range of interests led to his being labelled as an amateur by contemporaries who had a narrowly scientific focus. In Goethe's own words, his critics "forgot that science arose from poetry, and did not see that when times change the two can meet again on a higher level as friends". Although nature philosophy is long dead, such sentiments still find ready acceptance among alternative or 'holistic' philosophies. Anthroposophy - the world view of twentieth-century philosopher Rudolf Steiner - draws heavily on Goethe, and a germ of nature philosophy survives, if buried, in every anti-scientific, antiestablishment eco-warrior. Why has nature philosophy reinforced the idea of progressive evolution, given that it stems from a profoundly idealistic, pre-evolutionary view of life?

The unlikely fusion between evolution and nature philosophy was brokered by the zoologist Ernst Haeckel (1834-1919), who revered Goethe as a founding father of comparative anatomy. Haeckel was a product of the nineteenth-century school of German embryology that had been founded by nature philosophers, and it is largely thanks to him that we can now make, almost

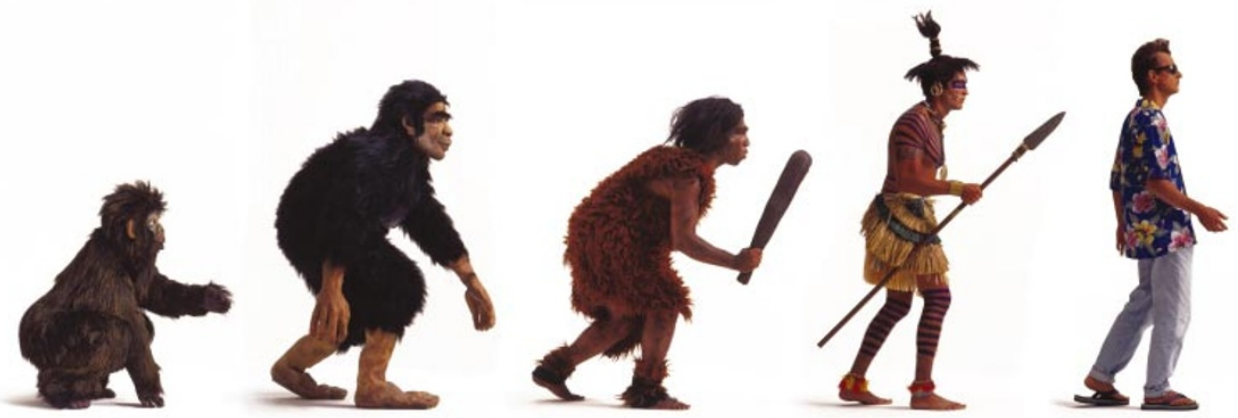

Hair today, gone tomorrow: popular culture still labours under the misapprehension that evolution is an inexorable climb culminating in humans, the last word in sophistication and sartorial savoir-faire.

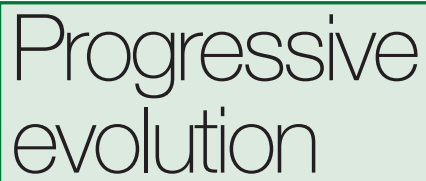

Those evolving-human commercials

are just nature philosophy brought

up to date.

without thinking, the connection between the embryogeny of individual organisms and the grand sweep of the progress of life on Earth. This link might not have been made as explicitly — or even at all — without nature philosophy. Indeed, one of Haeckel's students was Wilhelm Roux (1850-1924), a founder of modern developmental biology.

Haeckel visualized Darwin's natural selection as the engine driving a kind of evolution that ran on progressive, improving lines - a kind of animated nature philosophy. This line of thought produced, in other hands, the popular-culture model of evolution in which humans are the goal and the final statement.

Of course, natural selection is not a force, like gravity. It is directionless with respect to history; if there is direction in evolution (perhaps biased by developmental constraint), it is not propelled by any inherent drive for improvement. So why have modern scientists and so-called science popularizers failed to establish this truth in popular culture?

An obvious reason is that the progressive view resonates far more strongly with our own vanity and inclinations than with the more abstract and austere concept of evolution by mindless selection. In less enlightened times, progressive evolution was used to justify racism and Nazism. We like to think that we have risen above such things, but the copywriters know better - when we see the canonical parade of evolving humans, we identify with and aspire to be the one at the top.

Perhaps a more subtle explanation is that the progressive view is lodged in the minds of senior advocates of darwinian evolution by natural selection. As the late J. Z. Young wrote: "We shall expect to find in mammals even more devices for correcting the possible effects of external change than are found in other groups ... culminating in man with his astonishing perception of the 'World' around him and his powers of altering the whole fabric of the surface of large parts of the earth to suit his needs." Perhaps there is a nature philosopher in us all.

Henry Gee is a Senior Editor of Nature.

\section{FURTHER READING}

Young, J. Z. The Life Of Vertebrates 3rd edn (0xford Univ. Press, New York, 1981).

Huxley, T. H. Nature 1, 9-11 (1869). 